\title{
BIOÉTICA DESDE UNA PERSPECTIVA LATINOAMERICANA ${ }^{1}$
}

\author{
BIOETHICS FROM A LATIN AMRICAN PERSPECTIVE
}

\author{
ANTONIO BOSCÁN LEAL \\ Universidad del Zulia \\ asboscan@hotmail.com
}

\author{
JosÉ ViCENTE VILLALOBOS ANTÚNEZ \\ Universidad del Zulia \\ jvvillalobos@gmail.com
}

RECIBIDO: $25 / 07 / 2016$
ACEPTADO: $18 / 08 / 2016$

Resumen: La mayoría de los escritos especializados ponen a la bioética como una disciplina contemporánea originaria de una cultura altamente tecnificada, cuya creación ha servido para ayudar a establecer controles al desarrollo indiscriminado de la tecnociencia, sobre todo en su aplicación descontrolada a la vida en sus diferentes expresiones, con mayor énfasis en la humana, sin plena consciencia de sus efectos sobre el futuro de nuestra especie. Esto quiere decir que con la bioética se plantea coadyuvar en la resolución de problemas propios de una sociedad con muchos recursos materiales, altamente intelectualizada, pero todavía con deficiencias jurídicas, condicionada por una moral sin valores, y con una concepción ética que, muchas veces, antepone la autonomía del hombre sobre el bien común, la justicia distributiva y la espiritualidad del paciente. Pero, ¿qué rol puede jugar en las sociedades no tecnificadas ni intelectualizadas como las nuestras, donde prevalece la pobreza, las fallas en el sistema jurídico, y en las cuales no se ha logrado constituir una concepción estructurada de la persona humana? Por otro lado, ¿será posible darle un nuevo sentido a la bioética desde una realidad como la nuestra marcada por las luchas sociales y políticas, emprendidas por colectivos sensibilizados y con una consciencia crítica de su situación?

Palabras clave: Bioética, Latinoamérica, política, cultura, subdesarrollo.

\begin{abstract}
Most of the specialized writings put bioethics as a contemporary discipline originated in a highly technological culture whose creation has helped to establish controls for the indiscriminate development of technoscience, especially in its uncontrolled application to life in its different expressions with greater emphasis on the human, without full awareness of its effects on the future of our species. Therefore, with bioethics it is intended to contribute to solving the problems of a society with many material resources, highly intellectualized, but still with legal deficiencies, conditioned by a morality without values, and with an ethical conception that often puts the autonomy of man above the common good, the distributive justice and the spirituality of the patient. But what role can be

\footnotetext{
${ }^{1}$ El presente trabajo es producto del proyecto de investigación denominado: ÉTICA, TECNOLOGÍA $Y$ SOCIEDAD. EL PROBLEMA DE LA LIBERTAD EN EL MARCO DE LA SOCIEDAD TECNODEPENDIENTE que llevan los autores ante el Posdoctorado de Ciencias Humanas, de la Facultad de Humanidades y Educación de la Universidad del Zulia, Venezuela, período febrero 2016febrero 2017).
} 
played in non-technified and non-intellectualized societies such as ours, where poverty prevails, failures in the legal system, and in which a structured conception of the human person has not been achieved? On the other hand, will it be possible to give a new meaning to bioethics from a reality such as ours marked by social and political struggles, undertaken by sensitized groups and with a critical awareness of their situation?

Keywords: Bioethics, Latin America, politics, culture, underdevelopment.

\section{Introducción}

Desde hace aproximadamente más de una década se despertó nuestro interés por la bioética, al decidir crear la cátedra de bioética y más tarde la línea de investigación en nuestra Universidad, con la participación de los autores de este trabajo y de varios investigadores y docentes de diferentes áreas del conocimiento, con vistas a conformar un grupo interdisciplinario ${ }^{2}$.

Justamente, desde ese tiempo para acá, nuestro país viene atravesando una difícil situación, a todos los niveles, afectando seriamente la calidad de vida de todos los venezolanos, sin distinción. Esto ha propiciado en muchos colectivos aquejados por dicha situación, una recia crítica a las políticas implementadas en los últimos años por el Estado.

Es en este momento y bajo tales circunstancias que nos hemos propuesto un especial enfoque sobre la bioética. Uno de los trabajos que resaltamos en este artículo, son los publicados por los autores en diversas oportunidades desde donde se destacan situaciones al límite derivadas de los efectos sociales de la tecnociencia ${ }^{3}$; uno de ellos fue el resultado de reflexiones más tranquilas (Boscán, 2015), emprendidas dos años antes cuando la situación del país, y la personal de los autores, no había alcanzado el dramatismo en que ha caído este año, afligiéndonos con implacable rigor. Por eso, pensar en la bioética, en estas circunstancias, ha supuesto para nosotros, ahora, tratar de encontrar en su seno una orientación que nos permita proponer, aunque sea en forma teórica, alguna solución al conflicto general que nos afecta, caracterizado por un serio deterioro material y social. Así, pues, de momento, estamos impelidos a retomar la

\footnotetext{
2 En el cual participamos juristas, filósofos, politólogos, educadores, biólogos, médicos, antropólogos, economistas, administradores, ingenieros, entre otros profesionales no menos importantes.

${ }^{3}$ BOSCÁN LEAL, Antonio (2015): "La Bioética Feminista y la construcción actual del género" Revista Opcíón, Universidad del Zulia, Venezuela, Año 31, No. Especial 5 pp. 162-188. VILLALOBOS ANTÚNEZ, José Vicente y BELLO, Mariadela (2014): "Ética para una sociedad global: la bioética puente para el giro tecnocientífico", Revista Lasallista de Investigación, Corporación Universitaria Lasallista, Vol. 11, No. 1, pp. 70-77.
} 
bioética con otro interés, preguntándonos, primero, si vale la pena y si es posible hacer bioética en estas circunstancias, y, segundo, de qué forma puede ayudarnos la bioética a mantener la esperanza.

Las circunstancias que nos envuelven, nos han llevado, en ocasiones, a ver la bioética como otro producto específico de una cultura de abundancia, que no parece haber sido creada para dar respuesta a los problemas de países subdesarrollados como el nuestro, países que sufren desde hace mucho tiempo los desbarajustes de malas decisiones políticas. Pero, en el marco de las nuevas investigaciones que hemos emprendido en estos últimos tiempos, nos hemos tropezado con escritos, de autores hispanoamericanos, que viven en países con situaciones parecidas a la nuestra, planteando una serie de reflexiones y posturas críticas, serias e importantes, tales que nos han conducido a reconocer que sí es posible encontrar en la bioética fundamentos para la crítica y para dar una respuesta optimista. No obstante, algunos de esos autores hacen ver que esto sólo será posible si la bioética se flexibiliza y reorienta sus propósitos, es decir, si se logra que la misma se adapte a circunstancias nuevas, como las nuestras, para darle una utilidad distinta, original, lo cual puede contribuir a fortalecerla y a asegurarle una mejor posición en nuestra realidad.

En efecto, en varios de los tantos textos de que disponemos a la mano, encontramos varios artículos y libros de autores, repetimos, envueltos en situaciones como la nuestra, cuyos reflexiones y propuestas han renovado nuestro ánimo y nos han hecho repensar la bioética desde una nueva óptica, ayudándonos a revivir nuestro optimismo en el porvenir, siempre y cuando no permitamos que la bioética, ni otra disciplina ética y científica, pierda de vista la idiosincrasia y las necesidades particulares de las personas y grupos que recurren en auxilio a la misma.

\section{Bioética y política}

Uno de los primeros artículos con el que nos tropezamos fue el de Koldo Martínez, titulado "Bioética en los tiempos sombríos" (en Blanco Mercadé y Núñez Cubero, editores, 2014) ${ }^{4}$, que casualmente comienza con una reflexión parecida a la nuestra, sobre estos momentos difíciles que muchos países alrededor del mundo están viviendo:

\footnotetext{
${ }^{4}$ BLANCO MERCADÉ, Antonio y NÚÑEZ CUBERO, María, editores (2014) Edición Asociación de Bioética Fundamental y Clínica. Madrid.
} 


\begin{abstract}
¿A qué llamamos "tiempos sombríos"? En mi opinión, a esa sensación de tristeza, preocupación, anonadamiento, indignación, rabia, desesperación, impotencia, etc., que experimentamos cuando abrimos el periódico, encendemos la radio o la televisión, salimos de casa y nos encontramos con personas hurgando en la basura, hablamos con los amigos y nos cuentan su terrible situación de desempleo, vemos a nuestros hijos -la generación más y mejor formada de la historia de nuestro país- emigrar con su carrera, master e idiomas a otros países donde encuentran trabajo, cuando llegamos a nuestros centros de trabajo y sentimos la progresiva descomposición del sistema sanitario público, cuando participamos en movilizaciones sociales y nos damos cuenta de que muchas de estas situaciones son debidas a decisiones más o menos conscientes- de quienes han detentado y detentan el poder político con mayoría absoluta como ahora o con otro tipo de mayorías en otras ocasiones... Eso es lo que denominamos tiempos sombríos (en Blanco Mercadé y Núñez Cubero, editores, 2014:186).
\end{abstract}

En este párrafo introductorio, Martínez expone un panorama, en muchos sentidos, semejante al que se contempla hoy en Venezuela. Por supuesto, que hasta allí llega la comparación, porque estamos hablando de dos países, España y Venezuela, con diferentes estándares de vida hoy día.

En efecto, otro autor español, Juan Simó Miñana (en López Frías y colaboradores, 2013) $)^{5}$, habla de su país, como uno cuyo "gasto sanitario público y... riqueza han crecido durante las últimas décadas y se han aproximado al promedio de los países europeos más desarrollados." (en López Frías y colaboradores, 2013:61). Un país donde, como señala el mismo Simó, "Entre 1980 y 2007 nuestro PIB per cápita y nuestro gasto sanitario público per cápita, expresados ambos en dólares por paridad de poder adquisitivo, se han aproximado progresivamente al promedio europeo..." (en López Frías y colaboradores, 2013:62) De hecho, España es considerada una sociedad desarrollada, aunque no tanto como otros países de Europa; mientras que Venezuela todavía no ha salido de su condición de país tercermundista, dependiente y subdesarrollado; y tristemente hoy día plagado de miseria.

Sin embargo, en el ámbito científico, Koldo Martínez expresa que España:

...sufre una enorme y profunda división ideológica ante determinadas cuestiones relacionadas con problemas derivados de los avances científicotécnicos y de su repercusión en las vidas de los ciudadanos y ciudadanas,

\footnotetext{
${ }^{5}$ SIMÓ MIÑANA, Juan: "Nuestra sanidad pública: ¿Más eficiente que equitativa? ¿Más equitativa que eficiente?", en López Frías y colaboradores (2013) Bioética, Neuroética, Libertad y Justicia. Editorial Comares S. L., Granada.
} 
división que tiene implicaciones obvias en las conclusiones de los debates sobre el propio ser humano y las estructuras e instituciones fundamentales de la sociedad y que incluso puede a veces llegar a reflejar ciertos temores -no siempre infundados- respecto del poder de la tecnología o de los gobiernos (en Blanco Mercadé y Núñez Cubero, editores, 2014:186).

Esto quiere decir que en España, por ser un país con un nivel reconocido de progreso científico y tecnológico, sobre todo en el campo de la biotecnología, su población guarda ciertas preocupaciones con respecto a esos avances, algunos de los cuales hace varias décadas se han comenzado a aplicar con el objeto de mejorar la calidad de vida de las personas, asegurando así un lugar destacado a la investigación y la reflexión bioética.

Como consecuencia de ello, en España subsiste un debate ideológico entre los que se muestran a favor y los que se revelan en contra de esos avances científicos aplicados a la vida humana. Esto, al decir de Martínez, ha llevado a que cada día se preste una mayor atención al peso de lo ideológico en las decisiones políticas que tienen que ver con el avance científico. Y las investigaciones en el área de la bioética no pueden desatender este factor -el político-ideológico-, de modo que el autor propone reflexionar sobre la relación que pudiera establecerse entre bioética y política, entre bioética e ideología.

Una cosa es segura para Martínez: la ciencia no se orienta por fundamentos realmente neutrales, y esto debe comenzar a ser discutido por la bioética.

Martínez no sólo busca saber si es posible una aproximación de la bioética a la política, sino que, llevando la reflexión aún más lejos, quiere indagar el modo real en que la bioética -con su carácter interdisciplinario-, encaja en una sociedad pluralista y democrática, en la que el peso de lo político e ideológico es muy fuerte.

La bioética, como una nueva ética -tal como es concebida por Llano Escobar $(2001)^{6}$-, requiere ponérsela en relación con la política (y las relaciones de poder implícitas en ésta), en cuanto que $\operatorname{tal}^{7}$.

Martínez nos lleva a recordar que el surgimiento de dicha disciplina obedeció a factores morales, científicos, sociales y políticos, y que, desde el principio, se planteó cuestiones "que afectan a la relación moral entre el Estado y el

\footnotetext{
${ }^{6}$ LLANO ESCOBAR, Alfonso S. J. (2001) Editores LTDA, Bogotá

${ }^{7}$ También considera Martínez tener presente que, a la hora de poner en relación la ética con la política, nos encontraremos con dos posiciones contrarias, mediadas por dos concepciones del ser humano. Una la de los que sostienen que el ser humano es bueno por naturaleza, capaz de utilizar el poder en forma benéfica haciendo buenas políticas, y la otra, la de los que contrariamente afirman que es un ser tendiente a la perversidad, predispuesto a hacer un mal uso del poder y a establecer políticas inhumanas.
} 
individuo" (en Blanco Mercadé y Núñez Cubero, editores, 2014:188). Ciencia, ética y política muchas veces han tenido que relacionarse a la hora de establecer diversas políticas públicas.

Ahora bien, el asunto es que la tecnociencia biológica ha sido una de las áreas de mayor impacto en la vida humana en los últimos tiempos, y las controversias que ha generado la misma -y que dieron origen a la bioética-, han proliferado de tal modo que han sobrepasado el espacio de la plaza pública, y se han introducido en los lugares donde se plantean serios debates morales, pero también donde se instituyen leyes y se toman decisiones políticas.

Aquí Martínez no habla de la política como disciplina, sino de esa política en la que participan las y los ciudadanos, individual o colectivamente, influyendo en el ámbito legal y político, incluso en los cambios de gobierno. Esta política puede tener un carácter ético (cuando persigue el bien común) o un carácter inmoral (cuando propicia el egoísmo y la destrucción). En el primer caso, se toman decisiones recurriendo a la ética. Por este lado, según nuestro autor, la bioética puede servir para promover un buen diálogo entre científicos y políticos, contribuyendo a superar la brecha existente, hasta hoy, entre ambos.

Para Martínez, aquellos que han alcanzado una consciencia profunda de la realidad social en la que viven, se sienten obligados a tomar partido, bien sea decidiendo seguir la corriente de los acontecimientos que imponen un cambio histórico, o bien oponiéndose a dicho cambio; lo que no se puede es seguir siendo indiferente.

Y tomar una buena decisión política puede hacerse con ayuda de la bioética, lo cual no significa, para un bioeticista como él, querer politizarla. Lo que plantea es, si de verdad se aboga por un sistema democrático, concederle poder a los distintos sujetos políticos para que éstos den y se tomen en cuenta sus diversas opiniones sobre qué debe constituir una práctica ética.

También se debe propiciar que la comunidad bioética huya de las "guerras culturales" que han venido estableciendo los llamados bioeticistas progresistas (de izquierda) y los conservadores (de derecha). Y una forma de oponerse a esta guerra es precisamente favoreciendo una política participativa, la única capaz de evitar una distorsión o de impedir un mal uso de la bioética, y con la que se proporcionaría un modelo sensato de ética que sirva, a su vez, para frenar un mal uso de la política. Sólo así se alcanzaría una eficaz dialéctica civil, exenta de ineficaces y agrias polémicas, y se amortiguaría el poder de la intolerancia y el fanatismo, reforzándose la democracia.

Al decir de Martínez, a la bioética le corresponde contribuir a la instauración de la deliberación civilizada. ¿Cómo? Ayudando a exponer de manera realmente objetiva, las cuestiones que la sociedad o sus representantes no están en 
capacidad de responder adecuadamente. En este sentido la bioética puede "proporcionar razones fundadas para las posturas en conflicto y presentarlas públicamente de manera contenida y equilibrada" (en Blanco Mercadé y Núñez Cubero, editores, 2014:189).

Sería un error si la bioética se convierte en una cruzada moral a favor de los políticos de derecha o de izquierda. Debe respaldar una causa común, propiciando un diálogo civilizado.

Martínez recurre a Cohen de quien toma la propuesta de que la bioética ha de combinar la reflexión antropológica con el análisis de las políticas públicas, anteponiendo el respeto y la consideración de las opiniones bien tratadas de diferentes personas que conforman el espectro político de la sociedad. En tal sentido, la bioética, como saber razonado, debe coexistir con la bioética como labor política, sin quedar, como diría Macklin, también citado por Martínez, “subsumida en ella" (en Blanco Mercadé y Núñez Cubero, editores, 2014:190).

No hay otra forma mejor de resolver un desacuerdo político que hacerlo de forma democrática, porque en un sistema democrático se respeta el pluralismo y se trata a todas las personas como libres e iguales, autorizadas para tomar parte en el gobierno de la sociedad.

La democracia se fortalece con la deliberación, con el razonar en conjunto, manteniendo el respeto mutuo ante las diversas opiniones, que han de estar sujetas a los principios de reciprocidad, publicidad y responsabilidad. La deliberación realiza y profundiza la democracia, pero también ayuda a definir las diferencias de las y los ciudadanos, permitiéndoles separar las no tolerables. Ayuda a localizar puntos de acuerdo y de compromisos morales, así como aquellos irreductibles, haciendo efectivas a las comunidades políticas. Si las personas pueden hablar y vivir juntas, se afirma y avanza la sociedad ${ }^{8}$.

La pluralidad de éticas, mediadas por la deliberación, puede dar lugar a un acuerdo de ciertos principios éticos que sirvan para orientar las decisiones políticas.

Los principales problemas políticos derivan muchas veces de problemas éticos que no se han sabido resolver, pero también muchos problemas éticos son el resultado de serios dilemas políticos. Si el saber político se dirige a lo

\footnotetext{
${ }^{8}$ Martínez también destaca que la política no solamente se sustenta de la razón, sino también de la pasión, el compromiso, la solidaridad, la valentía, la competitividad sana. Pero, además, como la democracia resulta internamente contradictoria, porque en ella subsisten la virtud, el desinterés y la sociabilidad, al lado del egoísmo, la corrupción, la perversión y el rechazo al otro, el buen político, sin dejar de recurrir a la deliberación, en ocasiones ha de mantener el orden mediante la autoridad, el conflicto y la coerción. Aunque debe también dedicarse a fomentar la educación, el debate, la negociación, la persuasión.
} 
particular y a la pluralidad, y el ético es universalista y singular, y si la política tiene como objeto el buen gobierno de las y los ciudadanos asociados, entonces entre ética y política debe haber continuidad. Y es que las consideraciones sobre uno nos conducen irremediablemente al otro. Ninguna de ellas, por sí sola, puede alcanzar los objetivos políticos en una sociedad democrática, porque se trata de gestionar bien el poder en beneficio de todos.

"La ética proporciona la validación filosófica de una cuestión mientras que la política concede autorización para llevarla a cabo" (en Blanco Mercadé y Núñez Cubero, editores, 2014:192) y la autorización es producto de ciudadanos que se gobiernan a sí mismos entre sí mismos. Pero la validación es obra de un pensador que especula en solitario, apartado de la política, y en cuyo trabajo, como ocurre con el bioeticista, no interviene la democracia, por lo que ésta no le otorga derecho o privilegio alguno. Los aportes del filósofo y el bioeticista compiten en la misma medida con las opiniones de cualquier otro ciudadano 9 .

Concluye Martínez sosteniendo que la única ética válida hoy en día posible, es aquella que reconozca el mundo de la coexistencia humana, o sea, el mundo de la política. No puede basarse sólo en la verdad filosófica o científica, sino en la justicia, esto es, "en el arbitraje democrático y dialógico de las reivindicaciones en competición" (en Blanco Mercadé y Núñez Cubero, editores, 2014:192).

\section{Cultura, legislación y bioética}

Para Joaquín Jiménez y colabs. (en Blanco Mercadé y Núñez Cubero, editores, 2014), la ciencia y los avances tecnológicos por ella generados, siempre han resultado una importante herramienta para propiciar mejoras en el campo del bienestar social y la salud. Pero en muchas ocasiones esos avances han superado y puesto en juicio los conocimientos morales y éticos establecidos, creando controversia y suscitando la necesidad de comprensión y de regulación con medidas legales y argumentaciones filosóficas que terminan por encender el debate.

Son avances que han logrado hacer realidad hechos jamás supuestos pocos años atrás. En ocasiones, los mismos han conducido a que ciertos grupos

\footnotetext{
${ }^{9}$ De acuerdo a Ricoeur, citado por Martínez, en realidad, la verdadera intersección se da entre política, ética y economía. Y aunque los mecanismos económicos no reciben la validación de los filósofos ni la autorización expresa de las y los ciudadanos, repercute innegablemente en la vida de éstas/os. Por eso lo político debe mantener su autonomía, es decir no estar subordinada a lo económico-técnico, pero sí realizándose como accionar racional, apoyándose en la ética.
} 
opuestos a alterar el orden natural de la vida, los acepten y aprueben, siempre y cuando no contravengan sus principios religiosos o doctrinarios.

Lo importante es reconocer que esos avances alcanzados en los países más desarrollados, han llevado a la creación de un marco legislativo internacional que no ha resultado homogéneo, porque ha dependido de la forma como ha sido valorado y aceptado por cada cultura o estado.

A veces existe un amplio consenso entre varios países con respeto a la reglamentación de la aplicación de ciertas biotecnologías, por ejemplo, para el aborto, pero no siempre concuerdan en el momento de aplicarlas. No en todos los países con legislaciones similares, las mismas técnicas son admitidas, e incluso en algunos están prohibidas.

Fuera de ciertos marcos legislativos, como el europeo, la situación internacional es más complicada. Hay países donde existe una regulación por parte del Estado, otros en los que no; otros donde se siguen los preceptos de sociedades científicas y/o religiosas, y otros donde predominan muchos vacíos legales que no implican la prohibición del uso de la biotecnología.

La UNESCO, de acuerdo a Joaquín Jiménez y colabs., ha proclamado tres declaraciones, pero no son vinculantes a pesar de su fuerza legitimadora ${ }^{10}$. De modo que suceden muchos desplazamientos de individuos a otros países para acceder a determinadas técnicas en el área de la biotecnología, buscando escapar a las normas de sus países de origen, y ello sin un asesoramiento científico preciso y sin pensar en someterse a revisiones médicas cuando regresan a casa.

$\mathrm{Al}$ abrir nuevos horizontes desconocidos al ser humano, lo enfrentan a un duro debate con respecto a si aceptar todas sus posibilidades o juzgar que la biotecnología ha llegado muy lejos y, por tanto, requiere de restricciones. ¿Cuáles técnicas implicadas en la biotecnología se pueden aceptar y cuáles no?

Los puntos de desencuentro han generado diferentes tendencias bioéticas. De modo que subsiste la heterogeneidad en el marco legal respecto a la biotecnología. El debate ético suscitado por la biotecnología responde a los diferentes factores de influencia, lo que explica las particulares formas de tratarse en cada país.

Es necesario, en consecuencia, según Joaquín Jiménez y colabs., un análisis no sólo bibliográfico del marco legal, sino también sociocultural, económico y religioso de los diferentes países implicados con la instrumentación de ciertas o

\footnotetext{
${ }^{10}$ Véase una perspectiva de análisis de una de estas declaraciones en: VILLALOBOS ANTÚNEZ, José Vicente; HERNÁNDEZ, Juan Pablo y PALMAR, María (2012): "El estatuto bioético de los Derechos Humanos de Cuarta Generación", FRÓNESIS, Revista de Filosofía Jurídica, Social y Política. Universidad del Zulia, Venezuela. Vol. 19, No. 3, pp: 350-371.
} 
de todas las técnicas relacionadas con la biotecnología, sean éstas desarrolladas en el propio país o importadas de otros.

La religión es uno de los factores más importantes, que sigue influyendo de manera determinante no sólo en el estilo de vida de las personas, sino también en la política de muchos países, hasta imponer, en algunos casos, en enfoque individual acerca de las cuestiones bioéticas, lo que restringe la aplicación de buena parte de las terapias e investigaciones en este campo. El asunto es menos restrictivo en aquellos países o culturas de religión más liberal o cuyos sistemas políticos y legales están completamente divorciados del hecho religioso.

Por este lado, vemos como se anteponen los principios religiosos a los bioéticos, siendo ésta una clara señal de que no siempre predomina la racionalidad científica, ni una corriente de pensamiento desarrollada por consenso y dialógicamente por un grupo de ciudadanas/os, expertas/os o no.

En lo que respecta al factor económico, Joaquín Jiménez y colabs. reconocen la participación del Estado, como factor importante para el acceso universal a estas técnicas, pero esa ayuda estatal no está garantizada en todos los países. En algunos el Estado ofrece una financiación completa tanto si se realiza en centros de salud públicos como privados, dentro o fuera del país. Pero un mayor número de técnicas y a un más amplio número de personas se aplican en instituciones privadas, bajo autofinanciamiento. En todo caso, el monto financiado por el Estado depende del coste-beneficio, circunstancias sociales y familiares.

Hay países donde el Estado prácticamente no aporta nada para la asistencia financiera y jurídica, por lo que de las técnicas más significativas de la biotecnología se aprovechan sólo las clases pudientes. Y esto porque el Estado no interviene en las áreas relativas a la salud, prevaleciendo un importante vacío legal en asuntos referidos a este campo. No por casualidad en estos países se defiende a ultranza el principio de autonomía, y el problema o caso se plantea y se busca resolver en la sala de una institución privada, entre cliente y especialistas. Es en estas condiciones, en las que es posible la admisión de casos que han sido rechazados por legislaciones internacionales.

Esto no significa que esta visión individualista y liberal no se contraponga con ciertos derechos reivindicados por nuevos colectivos sociales y con la defensa, por parte de ciertas castas convencionales, de valores tradicionales, creando una mayor dificultad a nivel judicial que simplemente, en muchas ocasiones, no se busca resolver.

En regiones como en América Latina, la financiación ha dependido de la importancia que adquiera el debate bioético, en relación con otras áreas que se consideran prioritarias, lo cual ha redundado en una falta de legislación y un déficit estructural biotecnológico. Ello no impide que las clases con recursos 
paguen por los servicios que puedan prestar clínicas privadas especializadas en la aplicación de ciertas técnicas.

Las sociedades científicas han reaccionado frente a estas situaciones de una manera un tanto unánime: rechazando muchas de estas actitudes, ya que las mismas suponen un retraso científico dentro de un sistema global competitivo. Pero entienden que es muy fuerte el peso de las ideologías y de ciertas religiones en muchos países, así como el de la economía y la política. En algunos países la tradición tiene más fuerza que la ley, de modo que las autoridades legislativas, judiciales y ejecutivas, no se esfuerzan lo suficiente por hacer cumplir a esta última; en ellos son los sistemas familiares tradicionales o las personas con suficientes recursos las que terminan resolviendo sus necesidades en función de sus creencias, creencias muchas veces irracionales ${ }^{11}$.

Hay estados también, cuyas políticas sanitarias utilizan, en forma cuestionable, la biotecnología para realizar prácticas eugenésicas en su población. Pero igualmente los hay que critican la bioética occidental por desconocer ésta el contexto de cada cultura.

En conclusión, para Joaquín Jiménez y colabs., cuando se trata de resolver con ayuda de la bioética un caso concreto, no se pueden obviar las ideas propias y las del entorno. Más aun si ese paso lo tratan de dar personas de una cultura en la que no se hacen investigaciones bioéticas. No siempre las soluciones que presenta la bioética llegan a ajustarse a las necesidades reales de las personas o de un grupo social.

La bioética no puede pretender un acercamiento al individuo sin tomar en cuenta sus circunstancias presentes.

Otro aspecto al que hacen referencia Joaquín Jiménez y colabs., es la movilidad de culturas a nivel global y la relación intercultural directa o propiciada a través de los medios de comunicación y las TIC's, las cuales conducen a que, en sociedades democráticas y abiertas, ciertos valores tradicionales se cuestionen. Sin embargo, los factores sociales, económicos, tradicionales y religiosos propios de una cultura, no cabe duda de que siguen ejerciendo una fuerte influencia en el juicio y en el marco legal relacionado con la biotecnología.

El hecho más importante es que, ante el carácter multicultural que van adquiriendo la mayoría de las sociedades en el mundo, se debe buscar trascender las ideas tradicionales propias a la hora de analizar un caso concreto desde el punto de vista bioético, sobre todo cuando en el mismo está implicada otra

\footnotetext{
${ }^{11}$ Por ejemplo, utilizando la biotecnología para propiciar la fecundación de individuos únicamente masculinos.
} 
cultura, porque se requiere conocer la otra visión para realizar una valoración satisfactoria y completa. Se debe abogar, en consecuencia, por un acercamiento y una comprensión del entorno de otras culturas antes de emitir un juicio de valor respecto de ellas.

\section{Códigos éticos y políticas sociales}

Andreu García Aznar, en su artículo "Ser médico en tiempos sombríos" (en Blanco Mercadé y Núñez Cubero, editores, 2014), en la misma tónica de Joaquín Jiménez y colabs., sostiene que los códigos éticos se ven influenciados por el momento político social que en cada época vive una sociedad determinada. Es decir, que las leyes también se encuentran limitadas al territorio de aplicación, lo cual hace que un mismo hecho sea legal en un país, pero ilegal en otro, o tener matices diferentes en distintos países. Además, son susceptibles de ser modificadas por el color del partido gobernante o por la aceptación de o la resistencia a las presiones de ciertos grupos religiosos, laicos o de otra índole.

Así mismo, en ocasiones, pueden entrar en conflicto las leyes, o las decisiones judiciales, con los principios éticos.

Ahora bien, para Andreu García Aznar, si bien la bioética busca dar respuesta a los conflictos éticos que se suscitan en la investigación o en la práctica asistencial, sin embargo, las sociedades bioéticas no siempre exponen puntos de coincidencia, ya que pueden esgrimir opiniones parcial o totalmente contrapuestas, lo cual, no obstante, no se debe considerar algo irracional. Las opiniones diversas, argumentadas, enriquecen el debate y aportan visiones desde diferentes ópticas, por lo tanto, todas ellas deben ser tomadas en cuenta. Lo riesgoso se daría cuando el debate ser torna estéril y no se llega a acuerdos "que permitan la preservación y coexistencia lo más amplia posible de los diferentes valores dentro de un marco de derecho y respeto a las personas y su dignidad" (en Blanco Mercadé y Núñez Cubero, editores, 2014:685).

También hay que tener presente que algunos hechos públicos relevantes pueden sacar a la luz y hacer que cobren importancia concepciones morales diferentes, que de otro modo no se los hubiese prestado la debida atención.

Una sociedad plural como la que vivimos se caracteriza por el cruce permanente de opiniones y concepciones morales diferentes, que ponen de manifiesto los distintos valores que están presentes en esa sociedad, que si es democrática debe reconocer el derecho de los individuos a expresar libremente sus creencias y a opinar con plena libertad. Esto significa, para Andreu García Aznar, que no existe una única concepción moral para tratar todas las cuestiones 
y que si ante alguna de ellas se suscita el debate, debemos esforzarnos por llegar a un acuerdo.

Una ley puede entrar en conflicto con los valores de uno o de otras personas. ¿Se debe, entonces, cumplir la ley o hacer lo que uno considera moralmente correcto y que en ciertas sociedades se considera moralmente aceptable?

Los profesionales y las personas no pueden ser manipuladas caprichosamente por el gobierno de turno o cuando se cambie de gobierno, mucho menos en aquellas situaciones en las cuales la ley permite pero no obliga a ningún ciudadano a realizar los actos que dicha ley autoriza (en Blanco Mercadé y Núñez Cubero, editores, 2014:687). En tal caso se debe llegar a un pacto. La ley en cuestión debe abordarse pero mediante un "pacto amplio", que eche a un lado las diferencias políticas, máxime si se trata de un asunto sumamente delicado para la ciudadanía.

Siempre ha habido situaciones influenciadas por creencias, mitos e intereses particulares, que buscan limitar el trabajo de los eticistas, no obstante lo cual éstos han buscado siempre la manera de seguir adelante. Por otro lado, los eticistas tampoco dejan de tener sus propios valores y creencias que, en ciertas ocasiones, pueden entrar en conflicto con los valores y los derechos reconocidos por la ley que demandan las y los ciudadanos.

El eticista tiene el derecho de objetar a consciencia y ese derecho debe estar regulado para que no sea vulnerado ni sea causa de perjuicio para el profesional que lo ejerza honestamente. Pero la regulación también debe establecer los mecanismos de compensación necesarios para que tampoco se vulneren los derechos de las y los ciudadanos que serán atendidos por esos profesionales, y es responsabilidad de las instituciones preservar los derechos de unos y otros.

Los bioeticistas se ven implicados en todas aquellas situaciones que afectan la vida, y ante esas situaciones existen diversas concepciones morales y leyes que varían según la sociedad en la que estén inmersos. Y recordemos que las leyes convierten en legales o no las cosas, más no las convierten en buenas o malas.

Las leyes que actualmente predominan en una sociedad determinada están dirigidas a satisfacer los deseos de la mayoría, sin embargo, no deberían olvidar las necesidades de las minorías.

El hecho de que la actividad de los profesionales no debe estar supeditada a los cambios establecidos por el partido que pase a presidir un Estado, ni a la ideología de algún grupo de presión, implica que las diferentes sociedades de profesionales y colegios deben dedicarse a promover el debate entre los diferentes grupos sociales, con el fin de alcanzar consensos amplios que 
impliquen al mayor número de personas, dentro de un ambiente de respeto y de promoción de los derechos humanos.

Ante los tiempos difíciles que vivimos, sólo el diálogo entre los diferentes grupos de profesionales y sociales, permitirá alcanzar acuerdos que promuevan el progreso científico, así como el reconocimiento de los nuevos derechos que la sociedad va conquistando, aunque éstos puedan entrar en conflicto con los de nuestros antecesores y los cuales probablemente aun internamente preservamos.

La bioética ha avanzado y seguirá defendiendo al ser humano, a pesar de las incertidumbres y los conflictos y errores de las doctrinas y sistemas, y de los propios bioeticistas.

La ley nos obliga a todos pero el deber ético es anterior a la ley y cabe trabajar para que cada vez más uno y otro se vayan equiparando (en Blanco Mercadé y Núñez Cubero, editores, 2014:688).

\section{Bioética en América Latina}

El artículo de José Alberto Mainetti, "Bioética en América Latina" (Llano Escobar, 2001) ${ }^{12}$, nos ofrece una visión general de la forma como se ha introducido y trata de arraigar la bioética en Latinoamérica. Aunque está referido al ámbito médico asistencial, podemos extraer del mismo algunas generalidades que sirven a nuestro propósito de aproximación al estado de la bioética latinoamericana en la actualidad.

De acuerdo a Mainetti, la tradición católica ha definido la ética y el ethos profesional latinoamericanos. La teología católica ha construido un sistema de ética, normativo y aplicado, sustentado en tres aspectos: la moralidad está fundamentada en un derecho natural, el criterio moral es la santidad o inviolabilidad de la vida, y su regla, el amor y la caridad. Pero también ha reforzado el ethos profesional paternalista, acentuando un modelo beneficentista, el cual predomina hasta hoy.

Ésta no ha sido la tradición que ha prevalecido en la América anglosajona, marcada por el secularismo, el liberalismo y el pluralismo, como consecuencia de su desprendimiento de la metafísica y la religión y su adhesión a la racionalidad científica y política, lo que facilitó el desarrollo de una moral crítica y autónoma.

Después del proceso de independencia de los países latinoamericanos comienza la etapa de modernización de la enseñanza, el ejercicio y la política de

${ }^{12}$ LLANO ESCOBAR, Alfonso S. J. (2001) Editores LTDA, Bogotá. 
las profesiones. Pero no será sino en el siglo XX, cuando surgen las asociaciones profesionales y colegios encargados de formular sus propios códigos de ética, según la tradición deontológica que sirve para regular las relaciones de los profesionales de las diferentes áreas entre sí, con el público y el Estado.

El proceso de producción y modernización de los códigos ha continuado hasta hoy, obedeciendo a diversos factores como el progreso biomédico, los litigios por mala praxis y los cambios políticos locales, que sucedieron luego del derrocamiento de los regímenes militares.

A diferencia de los países angloparlantes, en América Latina el Estado ha asumido la responsabilidad en el área de la salud, teniendo un rango constitucional. Otro punto de diferencia es que, como reacción al modelo liberal, los derechos sociales y económicos, están consagrados en la constitución de muchos países latinoamericanos. Esta es una herencia del derecho civil o racionalismo jurídico romano, que busca que todo se prevea y formule en la legislación constitucional.

El Estado, según Mainetti, se ha constituido en algunos países de nuestra región en un ente planificador, que busca contemplar el acceso a los servicios esenciales por parte de las y los ciudadanos. Y la mejor forma que ha dispuesto para hacerlo es mediante un sistema público, gratuito o mutualizado.

Esta política estatal se ha visto impulsada por organismos internacionales que han surgido en la misma región.

En la década de los setenta del siglo pasado, sucedió un fracaso del modelo desarrollista, tomando impulso en ciertos países las propuestas neoliberales que propician un desarrollo local y descentralizado, con el que se pretende alcanzar una mayor apertura económica. Esto condujo a nuevas alternativas en el campo de la atención social, lo cual supuso un golpe a la vieja ética, todavía presente en los códigos deontológicos -expresión, en palabras de Mainetti, de una moral positiva dogmática y autoritaria, moral de autoridad profesional, a medias confesional y estatal-, a la que se ha opuesto una nueva ética representada por la bioética.

La bioética, que surgió como respuesta a los problemas derivados de la tecnificación de la vida, sustentada en una secularización de la moral, ha sido el resultado del cambio histórico propulsado por el progreso biotecnológico y por el carácter liberal y pluralista de los países industrializados.

Sin embargo, la bioética que se ha desarrollado en los países latinoamericanos sigue estando sujeta a una racionalidad "pretécnica" y a una moral "cerrada". En nuestro medio no se ha arraigado, como se ha intentado hacer en los países más desarrollados, una bioética como moral civil, sustentada 
en principios como la beneficencia, la autonomía y la justicia, ni siquiera como cultura preocupada por la introducción del sujeto moral.

Cuando en los ochenta comenzaron a implantarse en nuestros países nuevas tecnologías en el campo de la medicina, por parte de gobiernos democráticos, surgió el interés público y académico por los temas bioéticos. Sucedió al mismo tiempo una creciente intervención judicial en los casos médicos, como consecuencia del distanciamiento existente entonces entre profesional y paciente, de la mala praxis y del nuevo movimiento por los derechos del paciente, lo cual impulsó la práctica de la bioética, al estilo norteamericano. Este interés se acentuó en la academia, donde se comenzó rehabilitar la filosofía práctica, moral y política que comenzó a aplicarse en la medicina, tratando de seguir el modelo del pluralismo ideológico y la formación de consenso, instaurado en los países desarrollados.

Esto quiere decir, de acuerdo a Mainetti -quien exhorta a tomar en cuenta otros modelos, como el europeo-, que el desarrollo académico profesional de la bioética, en Latinoamérica, ha seguido el modelo norteamericano, incorporándolo, dadas las dificultades, en forma paulatina, y esto en virtud de que muchos de los profesionales nuestros promotores de estos estudios, se han formado en los Estados Unidos.

Sin embargo, de modo general, la institucionalización de la disciplina, así como la creación de centros de investigación, comités de ética en centros asistenciales, comisiones nacionales de bioética, entre otros, no ha sido muy amplia; y tampoco se ha cumplido programáticamente con las funciones educativa (la Deontología y la Medicina Legal mantienen el lugar de la ética en las escuelas de medicina), asistencial (en los hospitales y organismos de salud no se ejercita la ética clínica y sanitaria), y política (no se han constituido cuerpos de expertos que asesoren y hagan recomendaciones a los poderes públicos en normativas biomédicas).

Por otro lado, la bioética en nuestros países, acusa Mainetti, no ha llegado a las comunidades, porque no se ha hecho de la misma un movimiento de interés público y de los medios de comunicación social.

Actualmente, se han creado varias instituciones bioéticas en algunos países latinoamericanos, siendo los pioneros Argentina, en primer lugar, y Colombia, básicamente dedicadas a desarrollar programas de estudios bioéticos. Y cada día aumenta el número de personas interesadas en la disciplina, en participar en los cursos, conferencias, actividades científicas, así como también el de publicaciones, libros y artículos, especializadas en el área.

Es decir que aunque es poca aún la participación en el ámbito de la legislación y en la implementación de políticas públicas, notándose una mayor 
expansión en el área de la enseñanza académica, lo cual ha comenzado a redundar en la reformulación de los códigos en las asociaciones oficiales. Ya se pudiera, por lo tanto, hoy, se estarían dando las condiciones para el desarrollo de un programa integrador de los distintos centros que han surgido en la región y constituir una asociación latinoamericana que comience a dar respuesta a las necesidades y problemas propios de nuestro ámbito.

Hay problemas, de tipo macro, a los que, según Mainetti, se puede dar respuesta desde la perspectiva del bioderecho y de la biopolítica. No obstante, hay que realizar cambios a nivel legislativo y fomentar las políticas públicas, a la hora de afrontar realidades complejas y cambiantes, como las que suscita el desarrollo, por ejemplo, de la biomedicina.

Así tendríamos que una ética reproductiva ofrecería propuestas para romper con el círculo vicioso generado por el subdesarrollo y la superpoblación, círculo que se opone a un desarrollo sostenible. Hay que propiciar un debate público a este respecto y modernizar las leyes, y superar la política del dejar hacer. Las disputas habituales entre católicos y seculares, pudieran soliviantarse con una regulación jurídica sustentada en la bioética.

Aunque en el ámbito latinoamericano, la muerte no está medicalizada ni se ha dado un "asalto" tecnológico del morir, como ha sucedido en Norteamérica, la ortotanasia no deja de constituir un asunto de seria preocupación, cuya solución pudiera estar propiciada con el desarrollo de una ética tanatológica.

Un gran vacío legislativo y una ausencia de control prevalece en Latinoamérica en relación con la investigación biomédica, lo cual significa que la poca investigación de esta clase que se lleva a cabo suele carecer de validez científica y viola los derechos de los pacientes, al estar sometida a intereses crematísticos más que a la obtención de un conocimiento auténtico. No se propicia la propia investigación ni se establecen regulaciones locales a la hora de incorporar proyectos de cooperación internacional que pudieran dar lugar a la explotación económica y humana.

Si bien se necesita, en opinión de Mainetti, promover la creación de los comités de revisión ética, que tengan en cuenta los estándares internacionales, lo más importante es que se haga con criterios que se adecúen a las modalidades culturales de cada comunidad. Hay que tomar en cuenta las formas de moralidad propias, las cuales no siempre están acordes con los principios éticos de otras culturas.

La salud en América Latina está supeditada a las condiciones prevalecientes de subdesarrollo, pobreza, hambre y crisis económicas acentuadas por fuertes deudas externas. Los servicios de salud resultan insuficientes e inadecuados, "con despilfarro de recursos, falta de racionalización y deficiencias en los 
sistemas de seguridad social" (Llano Escobar, 2001:225) Ante el desafío de crear con urgencia una política social centrada en la salud, como indicador del desarrollo dirigido a satisfacer las necesidades básicas de la población, junto con la humanización de la atención médica basada en el acceso universal a la salud, una ética sanitaria es fundamental.

Existen muchos problemas ambientales en la región, y a pesar de la toma de consciencia pública y gubernamental y del esfuerzo que han hecho algunos países en legislar sobre el medio ambiente, promoviendo proyectos de conservación y protección de los recursos naturales, "la bioética no ha dicho todavía lo suyo a la comunidad y a los poderes públicos..." (Llano Escobar, 2001: 226)

La bioética, que comenzó identificando salud con bienestar y progreso con desarrollo cuantitativo, ahora define la salud como calidad de vida, y el progreso como desarrollo controlado o sostenible.

Por su tradición médica humanista y como región que busca su desarrollo, América Latina puede ofrecer, según Mainetti, una visión de la bioética distinta de la desarrollada en los países más desarrollados, porque muchos cuestionan de ésta un intento de humanización de la medicina sólo en apariencia, cuando se evidencia cierta deshumanización del sistema. Por ejemplo, el énfasis en la autonomía del paciente oculta, sin embargo, la despersonalización de la asistencia médica. Una fundamentación de la bioética en la antropología, la epistemología y la axiología médica, como por la que aboga Mainetti, puede ayudar a superar la razón positivista aún predominante y a proponer un modelo humanístico.

En Latinoamérica se plantea, en consecuencia, en opinión de Mainetti, la necesidad de una bioética con una orientación social, que acentúe el bien común, la buena sociedad y la justicia, deslindándose de la bioética, por ejemplo, anglosajona centrada en los derechos individuales y las virtudes personales. Frente a la ética micro o clínica angloamericana, propondría una ética macro de la salud o sanitaria.

Si la bioética de los países más desarrollados se ha enfocado en la manipulación de la vida y la liberación de la moral, una bioética latinoamericana, se centraría en un bios pretécnico y un ethos comunitario, que persiga, por ejemplo, la equidad en la asignación de recursos y en la distribución de los servicios de salud.

Tengamos presente que en los países más desarrollados, la bioética está en proceso de revisión de sus fundamentos, y se ha propuesto ampliar la aplicación de la ética a otros campos, como el político. También está redescubriendo la ética de la virtud, volviendo a lo experiencial y hasta propiciando el diálogo 
transcultural e internacional. La bioética en estos países está siendo cada vez más presionada por el alto costo de la salud, asociado al imperativo tecnológico de la medicina actual, y también por el abuso de la autonomía y por el derecho de las y los ciudadanos a la atención médica universal. Todo ello enmarcado en el tema de la justicia distributiva.

Ya no se puede seguir considerando que la atención médica sea un bien individual, de valor accesorio y pago privado; ha de ser considerada un bien social e individual, de gran beneficio y costo públicos.

Concluye Mainetti, señalando que la bioética ha de ser entendida como moral civil, ya que la misma debe promulgar la justicia social.

Su llamado es a acercar las propuestas bioéticas de los países desarrollados y los subdesarrollados, en el marco de un nuevo orden mundial. La bioética, tal como la concibió Potter, como "puente hacia el futuro", sólo se alcanzará por medio de la cooperación y la integración de perspectivas.

\section{Reflexión final a manera de conclusión}

En la Introducción de este ensayo, como producto de la situación que está atravesando nuestro país, y desde nuestra posición como participantes de la investigación bioética, nos hicimos las preguntas: ¿Vale la pena y es posible hacer bioética en las circunstancias críticas que estamos viviendo actualmente? Y, ¿de qué forma la bioética puede ayudarnos a mantener la esperanza?

Los planteamientos de los autores que hemos tomado en consideración en este ensayo creemos que nos han podido proporcionar elementos para responder, en forma afirmativa y optimista a estas cuestiones.

Lo primero que tenemos que señalar es que Martínez, Joaquín Jiménez (y colabs.), Andreu García Aznar y Mainetti coinciden en que sí es posible hacer bioética en tiempos difíciles, en los cuales pesan muchas dificultades materiales; eso sí, siempre y cuando se procure hacer ciertas adaptaciones. Es decir, siempre y cuando la bioética, como debe procurar hacerlo cualquier otra disciplina, se adapte a las circunstancias.

La posibilidad de que la bioética pueda hacer esto, se da por el hecho de que dicha disciplina no constituye una ética convencional cerrada, basada en principios establecidos a priori y que intente imponerlos sin tomar en cuenta no sólo las circunstancias que envuelven a cada persona y cada caso, sino considerando las circunstancias en las que ella misma se ve envuelta, ejerciendo innegable influencia sobre su campo de decisiones. 
Mainetti es muy claro en señalar que, si bien la bioética surgió en países altamente industrializados, como los Estados Unidos de Norteamérica, sus fundamentos no son para aplicarlos únicamente a esa clase de sociedad y de cultura. Puesto que la bioética nace y se sustenta del diálogo no sólo interdisciplinar sino del diálogo civil, y que si bien se pueden tomar como referencia los logros alcanzados por aquella en los países más desarrollados, la misma debe, no obstante, servir a los intereses sociales de países y culturas distintas, que como el nuestro obedecen a un bios pretécnico y a un ethos comunitario. En realidad, y en última instancia, debe nutrirse de un diálogo transcultural e internacional. Y nada de pretender imponer una bioética desde arriba o desde el exterior, cual verdad non plus ultra. Siendo fieles al sueño de Potter, su creador, la misma debe basarse en, y fomentar, la cooperación y la integración de perspectivas; sin embargo, a la hora de aplicarla, siempre hay que tomar en cuenta las circunstancias particulares.

Desde Latinoamérica, con sus conflictos y desigualdades, se ha luchado por la instauración de una moral civil, como fundamento esencial para alcanzar la justicia social. Y esto porque en nuestros países han venido surgiendo movimientos que luchan por la institucionalización y respeto de los derechos sociales y públicos de la ciudadanía, entre los cuales está la equidad en la asignación de recursos y la distribución de los servicios ${ }^{13}$. Este tipo de políticas se ha venido implementando en regímenes en los que el Estado se ha constituido en el ente planificador y regulador, que ha tratado de establecer un sistema público y gratuito.

Esto hace que la bioética que desde aquí se propone -lo cual no significa que lo haya efectivamente alcanzado-, tenga un carácter social, ya que se busca que coadyuve a afirmar el bien común, la buena sociedad y la justicia, por lo que no se pretende que esté acorde con esa clase de bioética generada en los países desarrollados, más centrada en los derechos individuales y las virtudes personales. Desde aquí se promueve una humanización del sistema de asistencia social, por lo que se plantea que la bioética contribuya al desarrollo de políticas sociales.

Otro asunto que se promueve desde nuestra realidad es la necesidad de fundamentar la bioética con una visión nueva: antropológica, epistemológica y

13 Para una perspectiva de los Derechos Sociales Fundamentales desde la Bioética, ver: VILLALOBOS ANTÚNEZ, José Vicente y GANGA, Francisco. 2016. "Derechos sociales fundamentales. Dualidad metodológica para una hermenéutica iusfilosófica de sus dilemas. Aproximación utópica desde la Bioética Global". Utopía y Prázxis Latinoamericana. Revista internacional de Filosofía iberoamericana y Teoría Social. Universidad del Zulia. Vol. 21, No 74. En prensa. 
axiológica, ya que, en razón de nuestra condición de países multiculturales, a la hora de proponer una solución desde la bioética, se debe tener en cuenta los rasgos de cada grupo social, sus propias concepciones del mundo y de la realidad y sus diferentes valores. Esto quiere decir que la bioética debe prestar su ayuda para establecer regulaciones locales $\mathrm{y}$, sin desatender los estándares internacionales, debe aplicar criterios de resolución de casos o problemas que se adecúen a las modalidades culturales de cada comunidad, cuyas formas de moralidad no siempre están acordes con los principios éticos de otras culturas.

El debate público en Latinoamérica está conduciendo a una modernización de las leyes; y en la institucionalización de una regulación jurídica adecuada y justa, la bioética, tal como la estamos redefiniendo, puede jugar un importantísimo papel. Sin estos cambios a nivel legislativo no es posible el despliegue de políticas de orden público, las únicas capaces de afrontar situaciones tan complejas y cambiantes como son las generadas no sólo por los avances biotecnológicos, sino por los conflictos sociales y medio ambientales que resultan característicos de nuestra región.

El hecho de que se promueva un nivel mayor de participación de la bioética en el ámbito de la legislación y en la implementación de políticas públicas, así como que se esté consolidando en el área de la enseñanza académica, no ha de considerarse como una moda, sino como el resultado de su naturaleza dialógica, no sólo a nivel de la interdisciplinariedad, sino a nivel de la ciudadanía.

Y esta contribución de la bioética, desde el ámbito académico, al diálogo civil, ha sido una propuesta hecha desde una realidad que no es la nuestra sino la de países que ya han superado su estado de subdesarrollo, como, por ejemplo, España, y que han comenzado a llamar la atención y a hacer reflexionar a los bioeticistas de los países altamente desarrollados, en los cuales se originó la bioética, pero donde no se ha llegado a hacer honor a los preceptos humanistas formulados por Potter, su creador.

La realidad, en nuestros países, lamentablemente es, como sostiene Mainetti, que la bioética no ha llegado a las comunidades, por lo que todavía no se ha convertido en un movimiento de interés público, que sea promovido por los medios de comunicación nuestros.

En países como España, por ejemplo, ya se ha superado esa condición, que a nosotros nos caracteriza todavía, de una Deontología y una Medicina Legal que no ha dado lugar a la ética; todavía no ejercitamos una ética clínica y sanitaria en nuestros centros de salud, y no se han podido constituir plenamente cuerpos de expertos que asesoren y hagan recomendaciones a los poderes públicos.

De acuerdo a Koldo Martínez, en España el debate bioético ya no se centra sólo en los problemas sociales generados por el desarrollo de la biotecnología, 
sino en el sentido que pueda tener aquella en una sociedad pluralista y democrática, en la que lo político y lo ideológico juegan un papel muy importante. No se trata de querer politizar la bioética, sino de prestar atención al hecho de que la bioética, desde su creación, estuvo implicada en cuestiones que afectan a la relación moral entre Estado e individuo, y que en sociedades auténticamente democráticas, tal implicación resulta ineludible a la hora de implementar políticas públicas.

Si reconocemos que la bioética no se limita solamente a discutir y hacer propuestas ante los conflictos generados por el desarrollo de la biotecnología, sino por cualquier tipo de avance tecnológico que afecte el futuro de la vida, sobre todo la humana, en este planeta, entonces se entenderá que ella siempre ha de estar presente en los debates morales que conducen a la institución de nuevas leyes y a la toma de decisiones políticas serias. El futuro de la humanidad es un asunto de importancia no sólo para los especialistas, sino para todas las personas y grupos que conforman el espectro político de la sociedad, porque se trata de una decisión de todos.

Para tomar las adecuadas decisiones políticas a este respecto, es decir que adquieran un carácter ético, ya que se trata de perseguir el bien común, una disciplina como la bioética viene a facilitar el diálogo entre científicos y políticos. En este sentido, en un sistema auténticamente democrático, donde se le conceda poder a los distintos sujetos políticos, al permitir que éstos den e intercambien sus distintas opiniones para encontrar una solución positiva -en base a unos acuerdos mínimos-, a un caso o problema que los afecte, la bioética puede jugar un significativo papel.

La bioética no busca desarrollar una ética convencional -elaborada de arriba hacia abajo- sino, como ya dijimos, una ética civil, esto es, producto de una decisión política. La bioética debe ser partidaria de una política participativa, ya que con ello evitaría caer en una distorsión o en un mal uso de la ética, lo que a su vez contribuiría a un empleo inadecuado de la política.

Estamos de acuerdo con Koldo Martínez en que la preocupación básica debe ser afirmar los valores democráticos de una sociedad, porque si no se han conquistado y no se disfrutan, es difícil establecer una dialéctica civil que contrarreste el poder de la intolerancia y el fanatismo.

La bioética vendría entonces a reforzar la instauración de una deliberación civilizada. Pero, de no haber tales condiciones, ¿qué podría proponer la bioética?

Para Martínez, el bioeticista ha de participar con sus opiniones en la vida política igual que cualquier otro individuo, y la democracia no le otorga ningún privilegio. Ahora bien, como se trata de un especialista que puede participar en la política pero que no ha de pretender politizar su disciplina, ni mucho menos 
partidizarla, y cuando las condiciones le cercenan la posibilidad de llevar a la práctica, junto con otros, una decisión consensuada, él puede seguir, como pensador solitario, trabajando en la validación filosófica de una cuestión ética, si es que temporalmente se ve apartado de la vida política. Y desde el reducido espacio en el que pueda trabajar, ha de utilizar los fundamentos de la bioética para seguir promoviendo la coexistencia humana, el diálogo civil y la política. Nunca podrá bastarle dedicarse sólo a la verdad filosófica o científica, sino luchar por la justicia, o como sostiene Joaquín Jiménez y colabs., por "el arbitraje democrático y dialógico de las reivindicaciones" (Blanco Mercadé y Nuñez Cubero: 192).

Haciendo referencia a lo sostenido por Joaquín Jiménez y colabs., en situaciones como en América Latina, sobre todo en aquellos países donde se trata de consolidar la democracia, se ha solido dar mayor importancia al desarrollo de otras áreas por considerarlas prioritarias.

Por ello es válido el planteamiento de Joaquín Jiménez y colabs., de la necesidad de que el bioeticista, además de dedicarse a un análisis bibliográfico del marco legal, deba emprender otro de tipo sociocultural, económico y religioso de las personas o grupos implicados en un asunto determinado.

En este sentido, el bioeticista debe estar claro de que existen factores, como el religioso o el económico, que pueden tener mayor peso que el científico, y que también, en ocasiones, ciertos valores morales se anteponen incluso a leyes o propuestas científicas. En algunos casos las decisiones políticas pueden no considerar para nada la racionalidad científica.

Es por ello que, según Joaquín Jiménez y colabs., la participación del Estado es fundamental, como factor que afirme los valores democráticos, es decir, un Estado que no se subordine a intereses partidistas, seculares o económicos.

Hay el caso de ciertos países en los que se privilegia el poder de los factores económicos, en detrimento de una intervención del aparato estatal para establecer un mayor control en la economía, y en favor del desarrollo de políticas públicas de beneficio social, pero es aquí donde el bioeticista puede recurrir al planteamiento de Mainetti de conformar asociaciones bioéticas internacionales que acaten las leyes internacionales-, para tener presente las propuestas de los profesionales de otros países, en los que las relaciones de poder se plantean de otra manera, si es que de verdad el bioeticista está claro en contribuir a la instauración de un nuevo orden mundial.

Los bioeticistas, de cualquier latitud, no pueden caer en el error, como sostiene Mainetti, de repetir los modelos de otros países, por muy civilizados que se consideren, ni mucho menos caer en la trampa del partidismo político, asumiendo el color de los partidos de derecha o de izquierda. 
Nada le quita al bioeticista que tenga, como individuo o ciudadano, sus propias convicciones políticas, pero en tanto que cultivador de una disciplina que busca establecer puentes, debe tener la capacidad de trascender sus propios valores, sin negarlos, y las de su entorno, para poder reconocer en sí mismo o a su alrededor, cualquier posición dogmática o intolerante en la que pueda estar inconscientemente incurriendo, y tener el coraje y sentir la necesidad de medir sus creencias con las de los bioeticistas de otras latitudes y culturas. Tampoco debe permitirse el bioticista de hoy proponer soluciones que no se ajusten a las necesidades reales de las personas o de un grupo social determinado.

Por otro lado, el bioeticista debe reconocer que las democracias actuales se nutren cada vez de encuentros interculturales, directos o propiciados por los medios de comunicación, y que en las sociedades más tolerantes y abiertas a estos intercambios, entran en juego nuevos valores, aumentando la confrontación, enriqueciendo el debate y anteponiendo una mayor necesidad de respeto y acuerdos, que imponen cambios constante en el marco legal, con el fin de alcanzar niveles mayores y más satisfactorios de convivencia.

En Latinoamérica, según coinciden Joaquín Jiménez y colabos. y Mainetti, no todos los Estados le han dado la importancia debida al debate bioético, ni han buscado financiar instituciones dedicadas al desarrollo de la bioética, pero aunque en ellos no se ha favorecido, como sí ha sucedido en ciertos países desarrollados, la creación de organizaciones especializadas, la alternativa que ha quedado ha sido impulsar, por parte de investigadores e intelectuales de diferentes especialidades, un movimiento que cada día se hace sentir con mayor fuerza dentro de las instituciones académicas, y por lo menos en ellas la bioética está cultivando, aunque de a poco, buenos frutos.

\section{Referencias bibliográficas}

BOSCÁN LEAL, Antonio (2015): "La Bioética Feminista y la construcción actual del género" Revista OPCIÓN, Universidad del Zulia, Venezuela, Año 31, No. Especial 5 pp. 162-188.

GARCÍA AZNAR, Andreu. "Ser médico en tiempos sombríos". En BLANCO MERCADÉ, Antonio y NÚÑ̃Z CUBERO, María Pilar. (Editores) 2014. La bioética y el arte de elegir. $2^{\mathrm{a}}$ edición. Asociación de Bioética Fundamental y Clínica. Madrid (España) pp. 683-689.

JIMÉNEZ GONZÁLEZ, Joaquín; SALCEDO HERNÁNDEZ, José Ramón; FERNÁNDEZ CAMPOS, Juan Antonio; ANDRÉU MARTÍNEZ, María Belén; HERNÁNDEZ MARTÍNEZ, Leticia Teresa; ESCOBAR ÁLVARO, Luis y 
QUESADA COSTILLA, Elena. "Factores que influyen en la legislación y juicio de diferentes culturas respecto a las técnicas de reproducción asistida (TRA) y el inicio de la vida". En BLANCO MERCADÉ, Antonio y NÚÑEZ CUBERO, María Pilar. (Editores) 2014. La bioética y el arte de elegir. $2^{\mathrm{a}}$ edición. Asociación de Bioética Fundamental y Clínica. Madrid (España) pp. 581-588. LLANO ESCOBAR, Alfonso. 2001. ¿Qué es Bioética? 3R Editores. Bogotá (Colombia)

MAINETTI, José Alberto. 1993. "Bioética en América Latina". En LLANO ESCOBAR, Alfonso. 2001. ¿Qué es Bioética? 3R Editores. Bogotá (Colombia). MARTÍNEZ URIONABARRENETXEA, Koldo. "Bioética en los tiempos sombríos". En BLANCO MERCADÉ, Antonio y NÚÑEZ CUBERO, María Pilar (Editores). 2014. La bioética y el arte de elegir. $2^{\mathrm{a}}$ edición. Asociación de Bioética Fundamental y Clínica. Madrid (España) pp. 186-193.

SIMÓ MIÑANA, Juan. "Nuestra sanidad pública: ¿más eficiente que equitativa? ¿más equitativa que eficiente?”, en LÓPEZ FRÍAS, Francisco Javier; MORALES AGUILERA, Paulina; SEBASTIÁN SOLANES, Raúl Francisco; GIL BLASCO, Marta; ARTETA ARILLA, Mikel; COSTA ALCARAZ, Ana María; GIMENO MONFORT, Xavier; PÁRAMO VALERO, Víctor; RUIZ RUBIO, Christian; ALBORCH BATALLER, Vicenta y NEBOT MARZAL, Cristina. (Editores) 2013. Bioética, neuroética, libertad y justicia. Editorial Comares, Granada (España) pp. 60-77.

VILLALOBOS ANTÚNEZ, José Vicente; HERNÁNDEZ, Juan Pablo y PALMAR, María. 2012: "El estatuto bioético de los Derechos Humanos de Cuarta Generación", FRÓNESIS, Revista de Filosofía Jurídica, Social y Política. Universidad del Zulia, Venezuela. Vol. 19, No. 3, pp: 350-371.

VILLALOBOS ANTÚNEZ, José Vicente y BELLO, Mariadela. 2014: "Ética para una sociedad global: la bioética puente para 1 giro tecnocientífico", Revista Lasallista de Investigación, Corporación Universitaria Lasallista, Vol. 11, No. 1, pp.: 70-77.

VILLALOBOS ANTÚNEZ, José Vicente y GANGA, Francisco. 2016. "Derechos sociales fundamentales. Dualidad metodológica para una hermenéutica iusfilosófica de sus dilemas. Aproximación utópica desde la Bioética Global". Utopía y Prázxis Latinoamericana. Revista internacional de Filosofía iberoamericana y Teoría Social. Universidad del Zulia. Vol. 21, No 74. En prensa. 
